\title{
ANALISIS KEPUASAN MAHASISWA TERHADAP PELAYANAN DI PERPUSTAKAAN UNIVERSITAS MUHAMMADIYAH GRESIK DENGAN METODE SERVQUAL TERINTEGRASI DENGAN IGA
}

\author{
Ardian Fanani ${ }^{1}$, Moh Dian Kurniawan ${ }^{2}$, Akhmad Wasiur Rizqi ${ }^{3}$ \\ Program Studi Teknik Industri, Fakultas Teknik, Universitas Muhammadiyah Gresik \\ Jl. Sumatera 101 GKB, Gresik 61121, Indonesia \\ e-mail : fardianhani99@gmail.com
}

\begin{abstract}
ABSTRAK
Perguruan tinggi adalah kelanjutan pendidikan yang dilakukan untuk mempersiapkan mahasiswa menjadi anggota masyarakat yang mempunyai kemampuan akademis dan professional. Perguruan tinggi mempunyai peranan yang sangat penting dalam peningkatan sumberdaya manusia. Salah satu aspek penting dalam sebuah perpustakaan adalah pelayanan. Pelayanan yang diberikan pustakawan adalah citra dari sebuah perpustakaan. Penelitian ini bertujuan untuk mengetahui kualitas pelayanan Perpustakaan Universitas Muhammadiyah Gresik, dilakukan untuk mengetahui atribut yang perlu perbaikan di perpustakaan Universitas Muhammadiyah Gresik. Metode Service Quality (SERVQUAL). Untuk menutupi kekurangan SERVQUAL peneliti menggunakan alat lainnya yaitu yaitu Improvement gap analysis (IGA). Berdasarkan hasil perhitungan SERVQUAL score yang didapatkan dalam mengukur kualitas pelayanan perpustakaan Universitas Muhammadiyah Gresik, didapatkan bahwa semua atribut yang digunakan dalam penelitian ini memiliki nilai SERVQUAL score negative yang berarti bahwa performa pelayanan perpustakaan Universitas Muhammadiyah Gresik belum sesuai dengan harapan mahasiwa. Sehingga kualitas pelayanan perpustakaan Universitas Muhammadiyah Gresik saat ini perlu dilakukan perbaikan. Atribut yang perlu untuk dilakukan perbaikan, berdasarkan metode IGA yaitu atribut yang terletak pada kuadran I. terdapat 4 atribut yang masuk dalam kuadran I, Usulan yang perlu untuk dilakukan perbaikan , terdapat 4 usulan, yaitu pihak perpustakaan Universitas Muhammadiyah Gresik menambah lagi koleksi buku-buku, penerapan $3 \mathrm{~s}$ (senyum, sapa, salam) lebih di tekankan lagi terutama sektor pelayanan dan juga petugas perpustakaan Universitas Muhammadiyah Gresik seharusnya mempunyai tata cara pelayanan agar saat penerapan pelayanan ke mahasiswa terus meningkat.
\end{abstract}

Kata kunci : Atribut, Improvement gap analysis (IGA), Kuadran Service Quality (SERVQUAL)

\begin{abstract}
Higher education is a continuation of education carried out to prepare students to become members of the community who have academic and professional abilities. Universities have a very important role in improving human resources. One of the important aspects in a library is service. The services provided by the librarian are the image of a library. This study aims to determine the service quality of the University of Muhammadiyah Gresik Library, conducted to determine the attributes that need improvement in the University of Muhammadiyah Gresik library. Service Quality (SERVQUAL) method. To cover the lack of SERVQUAL researchers used another tool, namely Improvement gap analysis (IGA). Based on the results of the calculation of the SERVQUAL score obtained in measuring the service quality of the University of Muhammadiyah Gresik library, it was found that all the attributes used in this study had a negative SERVQUAL score, which means that the performance of the University of Muhammadiyah Gresik library service has not been in accordance with student expectations. So that the quality of library services at the University of Muhammadiyah Gresik currently needs to be improved. Attributes that need to be improved, based on the IGA method, namely attributes that are located in quadrant I. There are 4 attributes that are included in quadrant I. Proposals that need to be improved, there are 4 proposals, namely the University of Muhammadiyah Gresik library to add more collections of books, the application of $3 s$ (smiles, greetings, greetings) is more emphasized, especially the service sector and also the librarian of the University of Muhammadiyah Gresik should have service procedures so that when the application of services to students continues to increase.
\end{abstract}

Keywords : Attributes, Improvement gap analysis (IGA), Service Quality Quadrant (SERVQUAL)

Jejak Artikel

Upload artikel : 1 Desember 2021

Revisi : 15 Desember 2021

Publish : 31Januari2022 


\section{PENDAHULUAN}

Perguruan tinggi adalah kelanjutan pendidikan yang dilakukan untuk mempersiapkan mahasiswa menjadi anggota masyarakat yang mempunyai kemampuan akademis dan profesional yang dapat mengembangkan, menciptakan dan menerapkan teknologi, ilmu pengetahuan dan kesenian Perguruan tinggi mempunyai peranan yang sangat penting dalam peningkatan sumberdaya manusia [1]. Perguruan tinggi bertugas menghasilkan lulusan yang berkualitas. Proses belajar mengajar saja tidak cukup, tentunya harus didukung dengan fasilitas pendukung terutama perpustakaanPerpustakaan merupakan aspek penting dalam perguruan tinggi, bahkan perpusatakaan juga sering di sebut "Jantung Perguruan Tinggi" [2].

Salah satu aspek penting dalam sebuah perpustakaan adalah pelayanan. Pelayanan yang diberikan pustakawan adalah citra dari sebuah perpustakaan. Pelanggan perpustakaan ialah orang yang ditemui ketika orang tersebut memerlukan dokuman primer atau menghendaki penelusuran biografi [3]. Semakin banyaknya mahasiswa atau masyarakat umum yang memanfaatkan perpustakaan, maka pelayanan perpustakaan harus berkualitas dikarena kegiatan pelayanan merupakan ujung tombak dari kegiatan yang dilaksanakan dalam sebuah pusat dokumentasi [4] .

Untuk mencapai tujuan pendidikan dan menjalankan fungsi Pendidikan tersebut, Lembaga akreditasi perpustakaan perpustakaan nasional (LAP-PNRI) telah menetapkan standar perpustakaan perguruan tinggi pada tahun 2013 [5]. Akreditasi perpustakan adalah evaluasi terhadap aspek-aspek penyelenggaraan perpustakaan apakah sudah sesuai dengan standar nasional perpustakaan Akreditasi perpustakaan. Akreditasi perpustakan adalah sebuah evaluasi yang dilakukan oleh pihak eksternal untuk menilai mendorong peningkatan kualitas dan efektifitas perpustakaan. Tujuan dari akreditasi ialah memperbaiki Lembaga yang diakreditasi. Perpustakaan yang masih belum memenuhi standart minimal dari standart perpustakaan nasional harus membenahi diri dan berupaya memperbaiki perpustakaannya supaya memenuhi standart minimal perpustakaan.

Sebuah perpustakaan akan mendapatkan sertifikat terakreditasi berdasarkan jumlah nilai tertimbang dari layanan, kerja sama, koleksi, pengorganisasian materi perpustakaan, sumber daya manusia, gedung/ruang, sarana prasarana, anggaran, dan manajemen perpustakaan dengan nilai minimal 60. Berikut ini tabel skor dan predikat penilaian, serta status perpustakaan yang diakreditasi.

Tabel 1 Skore Predikat Penilaian

\begin{tabular}{|l|l|}
\hline Nilai & \multicolumn{1}{|c|}{ Predikat Penilaian } \\
\hline $91-100$ & Akreditasi A (Amat Baik) \\
\hline $76-90$ & Akreditasi B (Baik) \\
\hline $60-75$ & Akreditasi C (Cukup Baik) \\
\hline$<60$ & Belum terakreditasi \\
\hline
\end{tabular}

Sumber : (Perpustakaan Nasional RI, 2012)

Menurut informasi dari hasil wawancara terhadap pegawai Perpustakaan Universitas Muhammadiyah Gresik (UMG) sekarang masih belum terakreditasi. Perpustakaan Universitas Muhammadiyah Gresik juga mempunyai visi menjadikan perpustakaan sebagai pusat informasi serta rujukan ilmiah yang mutakhir sekaligus berlandaskan nilai-nilai keislaman dalam mengoptimalkan pelaksanaan tri dharma perguruan tinggi.

Dalam akreditasi perpustakaan jumlah pengunjung berpengaruh dalam penilaian akreditasi perpustakaaan. Berikut adalah data jumlah pengunjung perpustakaan Universitas Muhammadiyah Gresik.

Tabel 1 Jumlah Pengunjung Perpustakaan Universitas Muhammadiyah Gresik

\begin{tabular}{|c|c|c|c|}
\hline Tahun & Pengunjung & $\begin{array}{c}\text { Jumlah } \\
\text { Mahasiswa }\end{array}$ & $\begin{array}{c}\text { Persentase } \\
(\mathbf{\%})\end{array}$ \\
\hline 2017 & 3012 & 4142 & $73 \%$ \\
\hline 2018 & 2808 & 4175 & $67 \%$ \\
\hline 2019 & 3497 & 4585 & $76 \%$ \\
\hline $\begin{array}{c}\text { Januari- } \\
\text { Oktober } \\
\text { 2020 }\end{array}$ & 1860 & 4976 & $37 \%$ \\
\hline
\end{tabular}

Sumber data: Perpustakaan Universitas Muhammadiyah Gresik 2020

Ada faktor yang mengakibatkan pengunjung pada tahun 2020 menurun derastis yaitu dengan kebijakan kampus yang mengubah kuliah menjadi online akibat pandemic covid-19. Berikut adalah instrument akreditasi perpustakaan perguruan tinggi tentang pengunjung perpustakaan. 
Tabel 2 Instrumen Akreditasi Perpustakaan Berdasarkan jumlah rata-rata pengunjung perpustakaan per bulan dalam satu tahun

\begin{tabular}{|c|c|}
\hline \multicolumn{2}{|c|}{ Jumlah mahasiswa 2001 s/d 10.000 orang } \\
\hline Jumlah & Nilai \\
\hline 10.000 orang atau lebih & $\mathrm{A}$ \\
\hline $8.000-9.999$ orang & $\mathrm{B}$ \\
\hline $7.000-7.999$ orang & $\mathrm{C}$ \\
\hline $6.000-6.999$ orang & $\mathrm{D}$ \\
\hline Kurang dari 6.000 orang & $\mathrm{E}$ \\
\hline $\begin{array}{c}\text { Bedasarkan instrument } \\
\text { perpustakaan pengunjung akreditasi } \\
\text { perpustakaan }\end{array}$
\end{tabular}
Universitas Muhammadiyah Gresik masih kurang dari 6000 setiap tahunnya, sehingga berdasarkan instrument penggunjung perpustakaan , perpustakaan Universitas Muhammadiyah Gresik bernilai E. Begitupun dengan data peminjam buku setiap tahunnya masih sangat rendah. Jika dinilai dengan instrumen penilaian perpustakaan jumlah ratarata buku yang dipinjam perbulan dalam satu tahun perpustkaan Universitas Muhammadiyah Gresik bernilai E [6] .

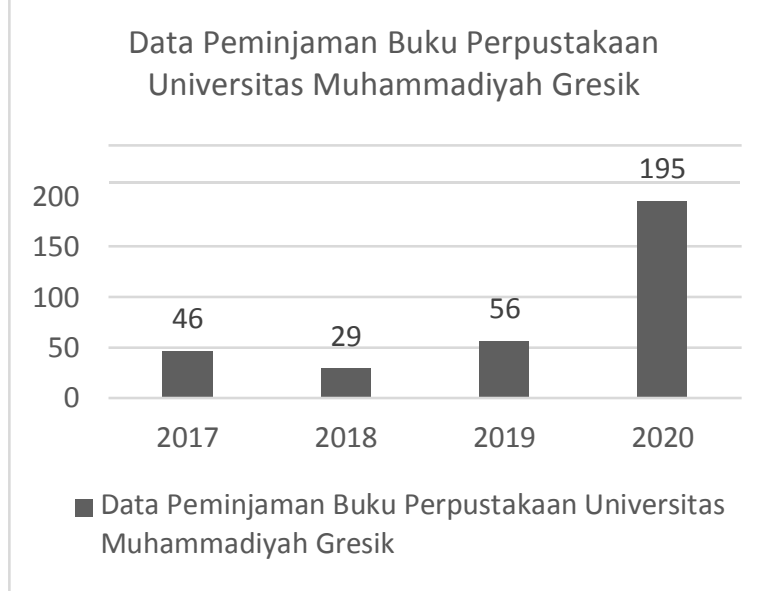

Gambar 1 Data Peminjaman Buku Perpustakaan Universitas Muhammadiyah Gresik

Tabel 3 Instrumen Penilaian Perpustakaan Berdasarkan Peminjam Buku

\begin{tabular}{|c|c|}
\hline $\begin{array}{c}\text { Jumlah rata-rata buku yang dipinjam per } \\
\text { bulan dalam satu tahun }\end{array}$ \\
\hline Jumlah Peminjam & Nilai \\
\hline 6.000 eks atau lebih & $\mathrm{A}$ \\
\hline $5.000-5.999 \mathrm{eks}$ & $\mathrm{B}$ \\
\hline $4.000-4.999 \mathrm{eks}$ & $\mathrm{C}$ \\
\hline $3.000-3.999 \mathrm{eks}$ & $\mathrm{D}$ \\
\hline
\end{tabular}

\begin{tabular}{|l|c|}
\hline Kurang dari 3.000 eks & E \\
\hline
\end{tabular}

Dalam konteks pengukuran variabel kualitas pelayanan, ada lima dimensi ukuran kualitas layanan yaitu reliability, responsiveness, assurance, tangible, dan empathy [7]. Ada beberapa metode yang dapat digunakan untuk mengukur kepuasan dari suatu layanan. Metode Service Quality (SERVQUAL) adalah salah satunya. Metode Service Quality (SERVQUAL) dipilih karena mempunyai dimensi metode SERVQUAL bisa digunakan untuk alat yang valid pengukuran gap antara pelayanan yang diperoleh dan yang diharapkan dari mahasiswa. SERVQUAL atau kualitas jasa didefinisikan sebagai penilaian atau sikap global berkenaan dengan superioritas suatu jasa. Sedangkan definisi kualitas layanan yang sering disebut sebagai mutu pelayanan adalah seberapa jauh perbedaan antara kenyataan dan harapan para pelanggan atas pelayanan yang mereka terima atau peroleh [8].

Kualitas pelayanan petugas perpustakaan dengan indikator kehandalan, empati, jaminan, daya tanggap, dan bukti langsung berpengaruh signifikan terhadap kepuasan mahasiswa yang artinya dimensi kualitas pelayanan memberikan pengaruh terhadap kepuasan mahasiswa dalam

telah dilakukan [9]. Variabel kualitas pelayanan adalah dengan indikator bukti fisik, keandalan, ketanggapan, jaminan, dan empati berpengaruh positif terhadap kepuasan mahasiswa, dengan aspek yang paling dominan yaitu keandalan dan empati. Harapan merupakan keinginan para pelanggan dari pelayanan yang mungkin diberikan [10].

Walaupun SERVQUAL bisa digunakan sebagai kerangka kerja untuk mengukur sebuah kualitas pelayanan dari berbagai industri namun masih terdapat kritik teoretis, operasional, konseptual, dan empiris tentang model ini [11]. Salah satu kritiknya yaitu batasan utama model SERVQUAL ialah ketidakmampuannya dalam memberikan perbaikan lebih lanjut pada titik lemah yang diidentifikasi dari kualitas layanan [12]. Sehingga untuk menutupi kekurangan SERVQUAL peneliti menggunakan alat lainnya yaitu yaitu Improvement gap analysis (IGA). IGA merupakan suatu analisis kuadran sederhana untuk mengarahkan upaya perbaikan yang dilakukan oleh suatu perusahaan yang 
berhubungan dengan excitementattributes dan basicattributes. Excitementattributes yang dimaksud merupakan atribut unik dari suatu perusahan yang berpengaruh terhadap kepuasan konsumen, sedangkan basicattributes merupakan atribut dasar yang diharapkan dimiliki oleh seluruh perusahaan sejenis. Improvement gap analysis (IGA) adalah metode yang dipakai untuk mengukur kualitas pelayanan dengan membandingkan seberapa besar celah antara kepuasan pelanggan dengan ketika suatu atribut mempunyai performansi yang rendah dengan dampak bagi kepuasan pelanggan Ketika suatu atribut mempunyai performansi yang lebih tinggi [13]. Sehingga Improvement gap analysis $(I G A)$ merupakan metode yang dapat digunakan dalam memperbaiki kualitas layanan dilihat dari kepuasan pelanggan.

\section{METODOLOGI PENELITIAN}

Penelitian ini dilakukan di Perpustakaan Universitas Muhammadiyah Gresik. Penelitian ini menggunakan metode kuantitatif. Metode kuantitatif ialah penelitian yang digunakan untuk meneliti pada sampel atau populasi tertentu. Data yang digunakan dalam penelitian adalah data primer dan data skunder. Data primer adalah data yang di peroleh dengan survey kepada responden, responden di penelitian ini adalah mahasiswa aktif s1 2020/2021 Universitas Muhammadiyah Gresik. Data sekunder merupakan sumber data yang diperoleh secara tidak langsung atau bukan asli seperti dari majalah, buku atau surat kabar.

Variabel di penelitian ini adalah variable yang berisi lima dimensi atribut Service Quality. Atribut ini merupakan adaptasi dari penelitian dan juga Komparasi Kondisi eksisting dengan 9 (sembilan) komponen penilaian akreditasi perpustakaan. Untuk mendapatkan atribut yang dapat mewakili keadaan sebenarnya penelitian ini menggabungan dari penyusunan atribut dari beberapa peneliti pada tabel 5 [14].

Tabel 5 Identifikasi Variabel

\begin{tabular}{|c|c|l|c|}
\hline No & Indikator & \multicolumn{1}{|c|}{ Dimensi } & Sumber \\
\hline \multirow{2}{*}{1} & Tangible & $\begin{array}{l}\text { Penampilan petugas } \\
\text { perpustakaan baik } \\
\text { dan rapi }\end{array}$ & {$[15]$} \\
\cline { 3 - 4 } & \begin{tabular}{c} 
(Bukti \\
\cline { 3 - 4 }
\end{tabular} & $\begin{array}{l}\text { Informasi } \\
\text { Fenempatan buku } \\
\text { sangat jelas dan } \\
\text { mudah di temukan }\end{array}$ & {$[15]$} \\
\hline
\end{tabular}

\begin{tabular}{|c|c|c|c|}
\hline & & $\begin{array}{l}\text { Sarana dan } \\
\text { prasarana seperti } \\
\text { meja, kursi, AC, } \\
\text { Wifi yang dimiliki } \\
\text { perpustakaan sudah } \\
\text { baik }\end{array}$ & [15] \\
\hline & & $\begin{array}{l}\text { Kebersihan di } \\
\text { dalam ruang } \\
\text { perpustakaan sudah } \\
\text { baik }\end{array}$ & [15] \\
\hline \multirow{4}{*}{2} & \multirow{4}{*}{$\begin{array}{l}\text { Reliability } \\
\text { (Kehandal } \\
\text { an) }\end{array}$} & $\begin{array}{l}\text { Penyampaian } \\
\text { informasi petugas } \\
\text { perpustakaan sudah } \\
\text { baik }\end{array}$ & [15] \\
\hline & & $\begin{array}{l}\text { Pelayanan } \\
\text { peminjaman buku } \\
\text { dilayani dengan } \\
\text { baik } \\
\end{array}$ & [16] \\
\hline & & $\begin{array}{l}\text { Koleksi buku sesuai } \\
\text { dengan kebutuhan } \\
\text { mahasiswa }\end{array}$ & [16] \\
\hline & & $\begin{array}{l}\text { Karyawan selalu } \\
\text { dapat ditemui pada } \\
\text { jam kerja }\end{array}$ & [16] \\
\hline \multirow[t]{2}{*}{3} & \multirow{2}{*}{$\begin{array}{l}\text { Responsiv } \\
\text { ness } \\
\text { (Ketangga } \\
\text { pan) }\end{array}$} & $\begin{array}{l}\text { Kesigapan petugas } \\
\text { dalam memberitahu } \\
\text { mahasiswa yang } \\
\text { mengalami kendala }\end{array}$ & [17] \\
\hline & & $\begin{array}{l}\text { Pelayanan petugas } \\
\text { perpustakaan } \\
\text { dengan cepat dan } \\
\text { tanggap }\end{array}$ & [17] \\
\hline \multirow{3}{*}{4} & \multirow{3}{*}{$\begin{array}{c}\text { Assurance } \\
\text { (Jaminn) }\end{array}$} & $\begin{array}{l}\text { Petugas memiliki } \\
\text { pengetahuan dalam } \\
\text { menjawab } \\
\text { pertanyaan } \\
\text { pengguna }\end{array}$ & [15] \\
\hline & & $\begin{array}{l}\text { Jaminan kerahasian } \\
\text { data mahasiswa }\end{array}$ & [15] \\
\hline & & $\begin{array}{l}\text { Petugas bersikap } \\
\text { Sopan Terhadap } \\
\text { mahasiswa }\end{array}$ & [15] \\
\hline \multirow{3}{*}{5} & \multirow{3}{*}{$\begin{array}{c}\text { Emphaty } \\
\text { (Kepeduli } \\
\text { an } \\
\text { Empati) }\end{array}$} & $\begin{array}{l}\text { Petugas } \\
\text { memberikan } \\
\text { pelayanan dengan } \\
\text { ramah }\end{array}$ & [18] \\
\hline & & $\begin{array}{l}\text { Petugas selalu siap } \\
\text { sedia dalam } \\
\text { membantumahasis } \\
\text { wa menghadapi } \\
\text { masalah }\end{array}$ & [18] \\
\hline & & $\begin{array}{l}\text { Petugas sabar } \\
\text { dalam memberikan } \\
\text { pelayanan terhadap } \\
\text { mahasiswa }\end{array}$ & [18] \\
\hline
\end{tabular}


Mahasiswa mudah untuk mencari dan menemui petugas perpustakaan

\section{HASIL DAN PEMBAHASAN}

\section{A. Penentuan Jumlah Sampel}

Perhitungan jumlah sampel yang dibutuhkan berdasarkan rumus Slovin, adalah sebagai berikut:

$$
\begin{gathered}
n=\frac{N}{1+N{ }^{2}} \\
n=\frac{4976}{1+4976(0,05)^{2}}=370,23 ; \text { pembulatan } \\
\text { menjadi } 370 \text { sampel }
\end{gathered}
$$

Prosedur pengambilan sampel didasarkan pada ukuran sampel untuk

Masing - masing Fakultas secara prosporsional, sebagai berikut:

$$
\phi \theta=\frac{N}{N} n
$$

\begin{tabular}{|c|c|c|c|c|}
\hline No & Fakultas & 20 & $\frac{N_{i}}{N} n$ & $\begin{array}{l}\text { (pembulatan) } \\
\text { (p) }\end{array}$ \\
\hline 1 & $\begin{array}{l}\text { Fakultas } \\
\text { Teknik }\end{array}$ & 1397 & 4976 370 & 104 \\
\hline 2 & $\begin{array}{l}\text { Fakultas } \\
\text { Ekonomi } \\
\text { dan Bisnis }\end{array}$ & 1684 & $4^{1684}{ }^{370}$ & 125 \\
\hline 3 & $\begin{array}{l}\text { Fakultas } \\
\text { Pertanian }\end{array}$ & 194 & $\frac{194}{4976} 370$ & 14 \\
\hline 4 & $\begin{array}{l}\text { Fakultas } \\
\text { Keguruan } \\
\text { dan Ilmu } \\
\text { Pendidikan }\end{array}$ & 752 & $\frac{752}{4976} 370$ & 56 \\
\hline 5 & $\begin{array}{l}\text { Fakultas } \\
\text { Agama } \\
\text { Islam }\end{array}$ & 178 & $\frac{178}{4976} 370$ & 13 \\
\hline 6 & $\begin{array}{l}\text { Fakultas } \\
\text { Psikologi }\end{array}$ & 280 & $\frac{280}{4976} 370$ & 21 \\
\hline 7 & $\begin{array}{l}\text { Fakultas } \\
\text { Hukum }\end{array}$ & 91 & $\frac{91}{4976} 370$ & 7 \\
\hline 8 & $\begin{array}{l}\text { Fakultas } \\
\text { Kesehatan }\end{array}$ & 400 & $\frac{400}{4976} 370$ & 30 \\
\hline \multicolumn{2}{|c|}{ JUMLAH } & 4976 & 4976 $4976{ }^{370}$ & 370 \\
\hline
\end{tabular}

Penentuan jumlah sampel untuk-untuk fakultas tertera pada tabel berikut ini

Tabel 6 jumlah sampel untuk-untuk fakultas

Kebutuhan tersebut merupakan kebutuhan minimal, dalam artian jika lebih tidak menjadi persoalan

\section{B. Karakteristik Responden}

Dari pengolahan data kuisioner, di peroleh informasi mengenai karakteristik responden secara umum. Berikut ini adalah table pesebaran dan diagram karakteristik responden dari 380 responden yang mengisi kuisioner.

\section{Fakultas}

Dari kuisioner yang terkumpul, kemudian

\begin{tabular}{|c|c|c|}
\hline & kưltas & Responden \\
\hline 1 & Fakultas Teknik & 109 \\
\hline 2 & $\begin{array}{c}\text { Fakultas Ekonomi dan } \\
\text { Bisnis }\end{array}$ & 126 \\
\hline 3 & Fakultas Pertanian & 15 \\
\hline 4 & $\begin{array}{l}\text { Fakultas Keguruan dan } \\
\text { Ilmu Pendidikan }\end{array}$ & 56 \\
\hline 5 & Fakultas Agama Islam & 13 \\
\hline 6 & Fakultas Psikologi & 21 \\
\hline 7 & Fakultas Hukum & 10 \\
\hline 8 & Fakultas Kesehatan & 31 \\
\hline & JUMLAH & 380 \\
\hline
\end{tabular}
dilakukan pengolahan dan di dapatkan profil responden. Berdasarkan asal Fakultas sebagaiberikut.

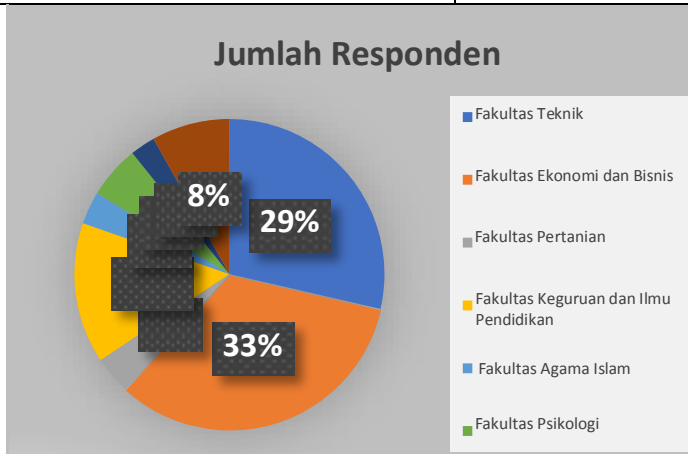

Gambar 2 Diagram lingkaran Jumlah Responden Berdasarkan Fakultas

\section{Pengolahan Data}

\section{- Uji Validitas dan Reabilitas}

Uji validitas dan reliabilitas dimaksudkan untuk mengetahui tingkat validitas item, maka dicari dulu nilai $r$ tabelnya. Nilai $r$ tabel dicari pada signifikansi 0,05 dengan nilai $\mathrm{df}=378$ (berasal dari jumlah responden 380 dikurangi 2), maka diperoleh angka 0,085. Selanjutnya nilai $r$ tabel dibandingkan dengan nilai $r$ hitung hasil dari olah data, dan item dinyatakan valid jika nilai $\mathrm{r}$ hitung $>\mathrm{r}$ tabel.

Dasar pengambilan keputusan dalam uji validitas adalah jika $\mathrm{r}$ hitung $>$ dari $\mathrm{r}$ tabel, maka 
item pertanyaan atau pertanyaan dalam angket berkorelasi signifikan terhadap skor total, atau dengan kata lain item angket dinyatakan valid. Dan jika sebaliknya $r$ hitung < r tabel, maka item pertanyaan atau pernyataan dalam angkat tidak berkorelasi signifikan terhadap skore total, atau dengan kata lain item angket tersebut tidak valid. Berikut adalah hasil dari Validitas dari hasil Quisioner yang di peroleh :

Tabel 8. Validitas Kuisioner SERVQUAL Presepsi

\begin{tabular}{|c|c|c|c|c|}
\hline Atribut & rhitung & & rtabel & Keterangan \\
\hline Tg 1 & 0,4 & $>$ & 0,085 & Valid \\
\hline Tg 2 & 0,587 & $>$ & 0,085 & Valid \\
\hline Tg 3 & 0,583 & $>$ & 0,085 & Valid \\
\hline Tg 4 & 0,54 & $>$ & 0,085 & Valid \\
\hline Rel 1 & 0,621 & $>$ & 0,085 & Valid \\
\hline Rel 2 & 0,686 & $>$ & 0,085 & Valid \\
\hline Rel 3 & 0,667 & $>$ & 0,085 & Valid \\
\hline Rel 4 & 0,709 & $>$ & 0,085 & Valid \\
\hline Res 1 & 0,777 & $>$ & 0,085 & Valid \\
\hline Res 2 & 0,774 & $>$ & 0,085 & Valid \\
\hline Ass 1 & 0,717 & $>$ & 0,085 & Valid \\
\hline Ass 2 & 0,603 & $>$ & 0,085 & Valid \\
\hline Ass 3 & 0,657 & $>$ & 0,085 & Valid \\
\hline Emp 1 & 0,73 & $>$ & 0,085 & Valid \\
\hline Emp 2 & 0,808 & $>$ & 0,085 & Valid \\
\hline Emp 3 & 0,772 & $>$ & 0,085 & Valid \\
\hline Emp 4 & 0,574 & $>$ & 0,085 & Valid \\
\hline Tabel & Vaidit Kuis & $S E R V 0$ & Ekspkasi \\
\hline
\end{tabular}

Tabel 9 Validitas Kuisioner SERVQUAL Ekspektasi

\begin{tabular}{|c|c|c|c|c|}
\hline Atribut & rhitung & & rtabel & Keterangan \\
\hline $\operatorname{Tg} 1$ & 0,683 & $>$ & 0,085 & Valid \\
\hline $\operatorname{Tg} 2$ & 0,688 & $>$ & 0,085 & Valid \\
\hline $\operatorname{Tg} 3$ & 0,707 & $>$ & 0,085 & Valid \\
\hline $\operatorname{Tg} 4$ & 0,74 & $>$ & 0,085 & Valid \\
\hline Rel 1 & 0,782 & $>$ & 0,085 & Valid \\
\hline Rel 2 & 0,733 & $>$ & 0,085 & Valid \\
\hline Rel 3 & 0,684 & $>$ & 0,085 & Valid \\
\hline Rel 4 & 0,797 & $>$ & 0,085 & Valid \\
\hline Res 1 & 0,838 & $>$ & 0,085 & Valid \\
\hline Res 2 & 0,844 & $>$ & 0,085 & Valid \\
\hline Ass 1 & 0,753 & $>$ & 0,085 & Valid \\
\hline Ass 2 & 0,794 & $>$ & 0,085 & Valid \\
\hline
\end{tabular}

\begin{tabular}{|c|c|c|c|c|}
\hline Ass 3 & 0,755 & $>$ & 0,085 & Valid \\
\hline Emp 1 & 0,829 & $>$ & 0,085 & Valid \\
\hline Emp 2 & 0,797 & $>$ & 0,085 & Valid \\
\hline Emp 3 & 0,767 & $>$ & 0,085 & Valid \\
\hline Emp 4 & 0,775 & $>$ & 0,085 & Valid \\
\hline
\end{tabular}

Tabel 10 Validitas Kuisioner IGA Current Satisfication

\begin{tabular}{|c|c|c|c|c|}
\hline Atribut & rhitung & & rtabel & Keterangan \\
\hline $\operatorname{Tg} 1$ & 0,705 & $>$ & 0,085 & Valid \\
\hline $\operatorname{Tg} 2$ & 0,72 & $>$ & 0,085 & Valid \\
\hline $\operatorname{Tg} 3$ & 0,747 & $>$ & 0,085 & Valid \\
\hline $\operatorname{Tg} 4$ & 0,653 & $>$ & 0,085 & Valid \\
\hline Rel 1 & 0,764 & $>$ & 0,085 & Valid \\
\hline Rel 2 & 0,745 & $>$ & 0,085 & Valid \\
\hline Rel 3 & 0,8 & $>$ & 0,085 & Valid \\
\hline Rel 4 & 0,667 & $>$ & 0,085 & Valid \\
\hline Res 1 & 0,681 & $>$ & 0,085 & Valid \\
\hline Res 2 & 0,769 & $>$ & 0,085 & Valid \\
\hline Ass 1 & 0,829 & $>$ & 0,085 & Valid \\
\hline Ass 2 & 0,67 & $>$ & 0,085 & Valid \\
\hline Ass 3 & 0,68 & $>$ & 0,085 & Valid \\
\hline Emp 1 & 0,741 & $>$ & 0,085 & Valid \\
\hline Emp 2 & 0,853 & $>$ & 0,085 & Valid \\
\hline Emp 3 & 0,777 & $>$ & 0,085 & Valid \\
\hline Emp 4 & 0,612 & $>$ & 0,085 & Valid \\
\hline
\end{tabular}

Tabel 11. Validitas Kuisioner IGA Fungsional

\begin{tabular}{|c|c|c|c|c|}
\hline Atribut & rhitung & & rtabel & Keterangan \\
\hline $\operatorname{Tg} 1$ & 0,66 & $>$ & 0,085 & Valid \\
\hline $\operatorname{Tg} 2$ & 0,842 & $>$ & 0,085 & Valid \\
\hline $\operatorname{Tg} 3$ & 0,644 & $>$ & 0,085 & Valid \\
\hline $\operatorname{Tg} 4$ & 0,808 & $>$ & 0,085 & Valid \\
\hline Rel 1 & 0,771 & $>$ & 0,085 & Valid \\
\hline Rel 2 & 0,821 & $>$ & 0,085 & Valid \\
\hline $\operatorname{Rel} 3$ & 0,898 & $>$ & 0,085 & Valid \\
\hline Rel 4 & 0,851 & $>$ & 0,085 & Valid \\
\hline Res 1 & 0,879 & $>$ & 0,085 & Valid \\
\hline Res 2 & 0,901 & $>$ & 0,085 & Valid \\
\hline Ass 1 & 0,756 & $>$ & 0,085 & Valid \\
\hline Ass 2 & 0,837 & $>$ & 0,085 & Valid \\
\hline Ass 3 & 0,808 & $>$ & 0,085 & Valid \\
\hline
\end{tabular}




\begin{tabular}{|c|c|c|c|c|}
\hline Emp 1 & 0,822 & $>$ & 0,085 & Valid \\
\hline Emp 2 & 0,808 & $>$ & 0,085 & Valid \\
\hline Emp 3 & 0,775 & $>$ & 0,085 & Valid \\
\hline Emp 4 & 0,861 & $>$ & 0,085 & Valid \\
\hline
\end{tabular}

Tabel 12 Validitas Kuisioner IGA Disfungsional

\begin{tabular}{|c|c|c|c|c|}
\hline Atribut & rhitung & & rtabel & Keterangan \\
\hline Tg 1 & 0,643 & $>$ & 0,085 & Valid \\
\hline Tg 2 & 0,745 & $>$ & 0,085 & Valid \\
\hline Tg 3 & 0,481 & $>$ & 0,085 & Valid \\
\hline Tg 4 & 0,633 & $>$ & 0,085 & Valid \\
\hline Rel 1 & 0,589 & $>$ & 0,085 & Valid \\
\hline Rel 2 & 0,79 & $>$ & 0,085 & Valid \\
\hline Rel 3 & 0,768 & $>$ & 0,085 & Valid \\
\hline Rel 4 & 0,477 & $>$ & 0,085 & Valid \\
\hline Res 1 & 0,621 & $>$ & 0,085 & Valid \\
\hline Res 2 & 0,661 & $>$ & 0,085 & Valid \\
\hline Ass 1 & 0,471 & $>$ & 0,085 & Valid \\
\hline Ass 2 & 0,532 & $>$ & 0,085 & Valid \\
\hline Ass 3 & 0,68 & $>$ & 0,085 & Valid \\
\hline Emp 1 & 0,476 & $>$ & 0,085 & Valid \\
\hline Emp 2 & 0,832 & $>$ & 0,085 & Valid \\
\hline Emp 3 & 0,69 & $>$ & 0,085 & Valid \\
\hline Emp 4 & 0,42 & $>$ & 0,085 & Valid \\
\hline
\end{tabular}

Selanjutnya, untuk melihat reliabilitas item. maka dapat dilihat dari nilai alpha cronbach ( ), dari hasil olah SPSS. Jika nilai > 0,6, maka item dinyatakan reliabel. Dari data tabel 4.7 dibawah, diketahui bahwa nilai untuk item item kuisioner Servqual Presepsi sebesar 0,765 > 0,6. Dengan demikian seluruh item tingkat Presepsi dinyatakan reliabel. Sedangkan untuk nilai untuk item item servqual Ekspektasi sebesar 0,765 > 0,6. Dengan demikian, seluruh item Ekspektasi dinyatakan reliabel. Selanjutnya untuk item item kuisioner IGA Current Satisfication sebesar $0,763>0,6$. Dengan demikian, seluruh item kuisioner IGA Current Satisfication dinyatakan reliabel. Untuk item-item kuisioner IGA Fungsional 0,767> 0,6. Dengan demikian, seluruh item kuisioner IGA Fungsional dinyatakan reliabel. Untuk item-item kuisioner IGA Disfungsional 0,747> 0,6. Dengan demikian, seluruh item kuisioner IGA Disfungsional dinyatakan reliabel

Tabel 13 Reabilitas Kuisioner SERVQUAL Presepsi
Reliability Statistics

\begin{tabular}{|c|r|}
\hline $\begin{array}{c}\text { Cronbach's } \\
\text { Alpha }\end{array}$ & N of Items \\
\hline .765 & 21 \\
\hline
\end{tabular}

Tabel 14 Reabilitas Kuisioner SERVQUAL Ekpektasi Reliability Statistics

\begin{tabular}{|r|r|}
\hline $\begin{array}{c}\text { Cronbach's } \\
\text { Alpha }\end{array}$ & N of Items \\
\hline .765 & 21 \\
\hline
\end{tabular}

Tabel 15 Reabilitas Kuisioner IGA Current Satisfication Reliability Statistics

\begin{tabular}{|c|r|}
\hline $\begin{array}{c}\text { Cronbach's } \\
\text { Alpha }\end{array}$ & Nof ltems \\
\hline .763 & 21 \\
\hline
\end{tabular}

Tabel 16 Reabilitas Kuisioner IGA Fungsional

Reliability Statistics

\begin{tabular}{|c|r|}
\hline $\begin{array}{c}\text { Cronbach's } \\
\text { Alpha }\end{array}$ & N of Items \\
\hline .767 & 21 \\
\hline
\end{tabular}

Tabel 17 Reabilitas Kuisioner IGA Disfungsional Reliability Statistics

\begin{tabular}{|r|r|}
\hline $\begin{array}{c}\text { Cronbach's } \\
\text { Alpha }\end{array}$ & N of Items \\
\hline .747 & 21 \\
\hline
\end{tabular}

Berdasarkan penghitungan uji validitas dan reliabilitas. dapat diketahui bahwa seluruh item telah valid dan reliabel, sehingga dapat dilanjutkan ke tahap uji selanjutnya.

\section{Perhitungan Service quality (SERVQUAL)}

- Perhitungan Tingkat Kepuasan

Nilai ini didapat dengan merata - rata ukur seluruh nilai dari tiap - tiap atribut yang ada dalam tingkat kepuasan (Nilai persepsi dan harapan pelanggan). Contoh Perhitungan:

Nilai persepsi :

$\frac{(1 \times 0)+(2 \times 4)+(3 \times 25)+(4 \times 249)+(5 \times 102)}{380}$

$=4,18$

Nilai ekpektasi:

$\frac{(1 \times 3)+(2 \times 0)+(3 \times 34)+(4 \times 216)+(5 \times 127)}{380}$
$=4,22$




\begin{tabular}{|c|c|c|}
\hline Atraibet 18 & Per|Pitessegasin tin & gkatKklesperalstasi \\
\hline $\operatorname{Tg} 1$ & 4,18 & 4,22 \\
\hline $\operatorname{Tg} 2$ & 3,65 & 4,41 \\
\hline $\operatorname{Tg} 3$ & 3,80 & 4,32 \\
\hline $\operatorname{Tg} 4$ & 4,11 & 4,41 \\
\hline Rel 1 & 3,85 & 4,33 \\
\hline Rel 2 & 3,92 & 4,23 \\
\hline Rel 3 & 3,55 & 4,36 \\
\hline Rel 4 & 3,64 & 4,29 \\
\hline Res 1 & 3,74 & 4,27 \\
\hline Res 2 & 3,77 & 4,38 \\
\hline Ass 1 & 3,77 & 4,33 \\
\hline Ass 2 & 3,96 & 4,53 \\
\hline Ass 3 & 4,11 & 4,35 \\
\hline Emp 1 & 3,96 & 4,36 \\
\hline Emp 2 & 3,70 & 4,32 \\
\hline Emp 3 & 3,86 & 4,40 \\
\hline Emp 4 & 3,96 & 4,27 \\
\hline
\end{tabular}

- Perhitungan nilai GAP Servqual

Pada sub bab ini akan ditampilkan hasil pengolahan data kuesioner dengan metode SERVQUAL berupa data tingkat kinerja dan harapan pada masing-masing atribut. Berikut merupakan contoh perhitungan nilai gap pada atribut Tg 1 (Penampilan petugas perpustakaan baik dan rapi )

$\mathrm{GS}=\mathrm{PS}-\mathrm{ES}=4,18-4,22=-0,04$

Dimana :

$\mathrm{PS}=$ Perception Score

$\mathrm{ES}=$ Expectation Score

Nilai gap negatif mengindikasikan bahwa harapanya tidak terpenuhi. Hal tersebut menunjukkan bahwa kinerja yang dirasakan mahasiswa terhadap pelayanan perpustakaan Universitas Muhammadiyah Gresik atribut Tg 1 belum memenuhi harapan mahasiswa. Berikut adalah hasil rekapan perhitungan Gap tiap atributnya.

Tabel 19 Nilai Gap SERVQUAL

\begin{tabular}{|c|c|c|c|}
\hline Atribut & Presepsi & Ekspektasi & Gap \\
\hline $\operatorname{Tg} 1$ & 4,18 & 4,22 & $-0,04$ \\
\hline $\operatorname{Tg} 2$ & 3,65 & 4,41 & $-0,76$ \\
\hline $\operatorname{Tg} 3$ & 3,80 & 4,32 & $-0,52$ \\
\hline $\operatorname{Tg} 4$ & 4,11 & 4,41 & $-0,31$ \\
\hline
\end{tabular}

\begin{tabular}{|c|c|c|c|}
\hline Rel 1 & 3,85 & 4,33 & $-0,47$ \\
\hline Rel 2 & 3,92 & 4,23 & $-0,31$ \\
\hline Rel 3 & 3,55 & 4,36 & $-0,81$ \\
\hline Rel 4 & 3,64 & 4,29 & $-0,65$ \\
\hline Res 1 & 3,74 & 4,27 & $-0,53$ \\
\hline Res 2 & 3,77 & 4,38 & $-0,62$ \\
\hline Ass 1 & 3,77 & 4,33 & $-0,56$ \\
\hline Ass 2 & 3,96 & 4,53 & $-0,57$ \\
\hline Ass 3 & 4,11 & 4,35 & $-0,24$ \\
\hline Emp 1 & 3,96 & 4,36 & $-0,40$ \\
\hline Emp 2 & 3,70 & 4,32 & $-0,62$ \\
\hline Emp 3 & 3,86 & 4,40 & $-0,53$ \\
\hline Emp 4 & 3,96 & 4,27 & $-0,31$ \\
\hline
\end{tabular}

\section{E. Perhitungan Improvement Gap Analysis}

(IGA)

Tabel merupakan data hasil pengolahan dengan menggunakan persamaanpersamaan pada metode Improvement Gap Analysis (IGA)

Tabel 20 hasil penghitungan Improvement Gap Analysis (IGA)

\begin{tabular}{|c|c|c|c|c|c|c|c|}
\hline No & $\begin{array}{c}\text { Atri } \\
\text { but }\end{array}$ & $\begin{array}{c}\text { AS } \\
\text { C }\end{array}$ & $\begin{array}{c}\text { AES } \\
\text { DQ }\end{array}$ & $\begin{array}{c}\text { AES } \\
\text { FQ }\end{array}$ & IG & $\begin{array}{c}\text { IG } \\
\text { k }\end{array}$ & $\begin{array}{c}\text { AES } \\
\text { DQk }\end{array}$ \\
\hline 1 & Tg 1 & $\begin{array}{c}1,1 \\
3\end{array}$ & 1,06 & 1,30 & $\begin{array}{c}0, \\
17\end{array}$ & $\begin{array}{c}- \\
1, \\
44\end{array}$ & $-1,10$ \\
\hline 2 & Tg 2 & $\begin{array}{c}0,8 \\
3\end{array}$ & $-0,07$ & 1,38 & $\begin{array}{c}0, \\
55\end{array}$ & $\begin{array}{c}0, \\
65\end{array}$ & 1,34 \\
\hline 3 & Tg 3 & $\begin{array}{c}1,0 \\
5\end{array}$ & 0,65 & 1,37 & $\begin{array}{c}0, \\
32\end{array}$ & $\begin{array}{c}- \\
63\end{array}$ & $-0,22$ \\
\hline 4 & Tg 4 & $\begin{array}{c}1,1 \\
6\end{array}$ & 0,79 & 1,38 & $\begin{array}{c}0, \\
22\end{array}$ & $\begin{array}{c}1, \\
15\end{array}$ & $-0,51$ \\
\hline 5 & $\begin{array}{c}\text { Rel } \\
1\end{array}$ & $\begin{array}{c}1,0 \\
0\end{array}$ & 0,48 & 1,29 & $\begin{array}{c}0, \\
29\end{array}$ & $\begin{array}{c}0, \\
80\end{array}$ & 0,14 \\
\hline 6 & $\begin{array}{c}\text { Rel } \\
2\end{array}$ & $\begin{array}{c}1,0 \\
9\end{array}$ & 0,36 & 1,52 & $\begin{array}{c}0, \\
43\end{array}$ & $\begin{array}{c}0, \\
02\end{array}$ & 0,42 \\
\hline 7 & $\begin{array}{c}\text { Rel } \\
3\end{array}$ & $\begin{array}{c}0,4 \\
3\end{array}$ & $-1,00$ & 1,42 & $\begin{array}{c}0, \\
98\end{array}$ & $\begin{array}{c}3, \\
08\end{array}$ & 3,38 \\
\hline 8 & $\begin{array}{c}\text { Rel } \\
4\end{array}$ & $\begin{array}{c}1,1 \\
6\end{array}$ & 0,90 & 1,49 & $\begin{array}{c}0, \\
34\end{array}$ & $\begin{array}{c}- \\
0, \\
52\end{array}$ & $-0,76$ \\
\hline 15 & $\begin{array}{c}\text { Res } \\
1\end{array}$ & $\begin{array}{c}1,0 \\
5\end{array}$ & 0,78 & 1,46 & $\begin{array}{c}0, \\
42\end{array}$ & $\begin{array}{c}- \\
0, \\
08\end{array}$ & $-0,49$ \\
\hline 11 & $\begin{array}{c}\text { Res } \\
2\end{array}$ & $\begin{array}{c}1,0 \\
0\end{array}$ & 0,80 & 1,43 & $\begin{array}{c}0, \\
43\end{array}$ & $\begin{array}{c}0, \\
02\end{array}$ & $-0,54$ \\
\hline 14 & $\begin{array}{c}\text { Ass } \\
1\end{array}$ & $\begin{array}{c}0,8 \\
8\end{array}$ & 0,66 & 1,46 & $\begin{array}{c}0, \\
57\end{array}$ & $\begin{array}{c}0, \\
80\end{array}$ & $-0,25$ \\
\hline $\begin{array}{c}\text { Ass } \\
3\end{array}$ & $\begin{array}{c}1,1 \\
2\end{array}$ & 0,91 & 1,57 & $\begin{array}{c}0, \\
45\end{array}$ & $\begin{array}{c}0, \\
10\end{array}$ & $-0,78$ \\
\hline
\end{tabular}




\begin{tabular}{|c|c|c|c|c|c|c|c|}
\hline 17 & $\begin{array}{c}\text { Emp } \\
1\end{array}$ & $\begin{array}{c}1,0 \\
4\end{array}$ & 0,45 & 1,44 & $\begin{array}{l}0, \\
40\end{array}$ & $\begin{array}{c}- \\
0, \\
15\end{array}$ & 0,22 \\
\hline 18 & ${ }_{2} \operatorname{Emp}$ & $\begin{array}{c}1,0 \\
6\end{array}$ & 0,51 & 1,38 & $\begin{array}{l}0, \\
33\end{array}$ & $\begin{array}{c}0, \\
58\end{array}$ & 0,09 \\
\hline 19 & $\begin{array}{c}\text { Emp } \\
3\end{array}$ & $\begin{array}{c}1,0 \\
3\end{array}$ & 0,82 & 1,41 & $\begin{array}{c}0, \\
38\end{array}$ & $\begin{array}{l}- \\
0, \\
25\end{array}$ & $-0,59$ \\
\hline 20 & $\begin{array}{c}\text { Emp } \\
4\end{array}$ & $\begin{array}{c}0,8 \\
9\end{array}$ & 0,67 & 1,51 & $\begin{array}{l}0, \\
62\end{array}$ & $\begin{array}{l}1, \\
06\end{array}$ & $-0,26$ \\
\hline $\begin{array}{l}\text { Rat } \\
a^{*}\end{array}$ & & & 0,55 & & $\begin{array}{l}0, \\
44 \\
\end{array}$ & & \\
\hline $\begin{array}{c}\text { ST } \\
\text { D } \\
\text { DE } \\
\text { V } \\
\end{array}$ & & & 0,46 & & $\begin{array}{l}0, \\
18\end{array}$ & & \\
\hline
\end{tabular}

Dari hasil pengolahan data seperti yang tersaji pada tabel 4.13, kemudian nilai Average Expectation with Disfunctional Question (AESDQk) yang terstadarisasi dan nilai improvement Gap (IGk) yang telah terstandarisasi ditampilkan ke matriks IGA pada gambar 4.2 matriks IGA. Nilai Improvement Gap yang terstandarisasi (IGk) merupakan sumbu x dan nilai Average Expectation with Disfunctional Question yang terstandarisasi

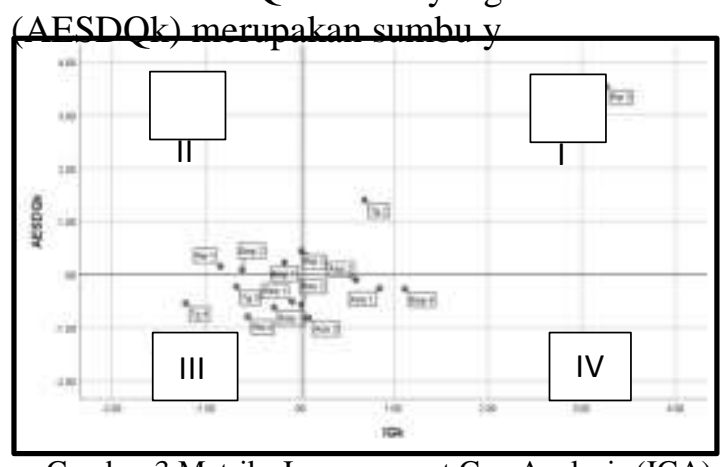

Gambar 3 Matriks Improvement Gap Analysis (IGA)

Pada diagram kartesius (gambar 4.2) diketahui atribut-atribut penilaian yang ada masuk ke dalam kuadran mana. Berikut adalah penjabaran dari matriks IGA:

1. Kuadran I (critical attribute)

Rel 3 = Koleksi buku sesuai dengan kebutuhan mahasiswa

$\operatorname{Tg} 2$ = Informasi penempatan buku sangat jelas dan mudah di temukan

Rel 2 = Pelayanan peminjaman buku dilayani dengan baik

\section{Kuadran II (keep current performance)}

Emp $1=$ Petugas memberikan pelayanan dengan ramah
Emp 2 = Petugas selalu siap sedia dalam membantu mahasiswa menghadapi masalah Rel $1=$ Penyampaian informasi petugas perpustakaan sudah baik

3. Kuadran III (neutral attribute)

$\operatorname{Tg} 3$ =Sarana dan prasarana seperti meja, kursi, AC, Wifi yang dimiliki perpustakaan sudah baik Res 1 =Kesigapan petugas dalam memberitahu mahasiswa yang mengalami kendala

$\operatorname{Tg} 4=$ Kebersihan di dalam ruang perpustakaan sudah baik

Rel 4 =Karyawan selalu dapat ditemui pada jam kerja

Emp 3 =Petugas sabar dalam memberikan pelayanan terhadap mahasiswa

$\operatorname{Tg} 1=$ =Penampilan petugas perpustakaan baik dan rapi

4. Kuadran IV (excitement attribute)

Ass 2 =Jaminan kerahasian data mahasiswa

Ass 1 =Petugas memiliki pengetahuan dalam menjawab pertanyaan pengguna

Emp 4 =Mahasiswa mudah untuk mencari dan menemui petugas perpustakaan

Res 2 =Pelayanan petugas perpustakaan dengan cepat dan tanggap

Ass 3 =Petugas bersikap Sopan Terhadap mahasiswa

\section{KESIMPULAN}

\section{A. Kesimpulan}

Didapatkan hasil perhitungan SERVQUAL score yang digunakan dalam mengukur kualitas pelayanan perpustakaan Universitas Muhammadiyah Gresik sebagai berikut.

\begin{tabular}{|c|l|c|}
\hline Kode & \multicolumn{1}{|c|}{ Atribut } & Gap \\
\hline Rel 3 & $\begin{array}{l}\text { Koleksi buku sesuai dengan } \\
\text { kebutuhan mahasiswa }\end{array}$ & $-0,81$ \\
\hline Tg 2 & $\begin{array}{l}\text { Informasi penempatan buku } \\
\text { sangat jelas dan mudah di } \\
\text { temukan }\end{array}$ & $-0,76$ \\
\hline Rel 4 & $\begin{array}{l}\text { Karyawan selalu dapat } \\
\text { ditemui pada jam kerja }\end{array}$ & $-0,65$ \\
\hline Res 2 & $\begin{array}{l}\text { Pelayanan petugas } \\
\text { perpustakaan dengan cepat } \\
\text { dan tanggap }\end{array}$ & $-0,62$ \\
\hline Emp 2 & $\begin{array}{l}\text { Petugas selalu siap sedia } \\
\text { dalam membantu } \\
\text { mahasiswa menghadapi } \\
\text { masalah }\end{array}$ & $-0,62$ \\
\hline
\end{tabular}




\begin{tabular}{|c|c|c|}
\hline Ass 2 & $\begin{array}{l}\text { Jaminan kerahasian data } \\
\text { mahasiswa }\end{array}$ & $-0,57$ \\
\hline Ass 1 & $\begin{array}{l}\text { Petugas memiliki } \\
\text { pengetahuan dalam } \\
\text { menjawab pertanyaan } \\
\text { pengguna }\end{array}$ & $-0,56$ \\
\hline Emp 3 & $\begin{array}{l}\text { Petugas sabar dalam } \\
\text { memberikan pelayanan } \\
\text { terhadap mahasiswa }\end{array}$ & $-0,53$ \\
\hline Res 1 & $\begin{array}{l}\text { Kesigapan petugas dalam } \\
\text { memberitahu mahasiswa } \\
\text { yang mengalami kendala }\end{array}$ & $-0,53$ \\
\hline $\operatorname{Tg} 3$ & $\begin{array}{l}\text { Sarana dan prasarana seperti } \\
\text { meja, kursi, AC, Wifi yang } \\
\text { dimiliki perpustakaan sudah } \\
\text { baik }\end{array}$ & $-0,52$ \\
\hline Rel 1 & $\begin{array}{l}\text { Penyampaian informasi } \\
\text { petugas perpustakaan sudah } \\
\text { baik }\end{array}$ & $-0,47$ \\
\hline Emp 1 & $\begin{array}{l}\text { Petugas memberikan } \\
\text { pelayanan dengan ramah }\end{array}$ & $-0,40$ \\
\hline Emp 4 & $\begin{array}{l}\text { Mahasiswa mudah untuk } \\
\text { mencari dan menemui } \\
\text { petugas perpustakaan }\end{array}$ & $-0,31$ \\
\hline $\operatorname{Rel} 2$ & $\begin{array}{l}\text { Pelayanan peminjaman } \\
\text { buku dilayani dengan baik }\end{array}$ & $-0,31$ \\
\hline $\operatorname{Tg} 4$ & $\begin{array}{l}\text { Kebersihan di dalam ruang } \\
\text { perpustakaan sudah baik }\end{array}$ & $-0,31$ \\
\hline Ass 3 & $\begin{array}{l}\text { Petugas bersikap Sopan } \\
\text { Terhadap mahasiswa }\end{array}$ & $-0,24$ \\
\hline $\operatorname{Tg} 1$ & $\begin{array}{l}\text { Penampilan petugas } \\
\text { perpustakaan baik dan rapi }\end{array}$ & $-0,04$ \\
\hline
\end{tabular}

Setelah melakukan penyebaran kuisioner. Terdapat 380 responden yang mengisi kuisioner. Dari kuisioner yang disebarkan melalu Google Form terdapat 20 atribut pertanyaan yang harus di isi oleh responden, ternyata dari 20 atribut tersebut semua memiliki nilai negative sehingga atribut tersebut diperlukanya intergrasi dengan metode IGA dengan ini dapat disimpulkan kualitas pelayanan perpustakaan Universitas Muhammadiyah Gresik saat ini perlu dilakukan perbaikan.

Atribut yang perlu untuk dilakukan perbaikan, berdasarkan metode IGA yaitu atribut yang terletak pada kuadran I. terdapat 4 atribut yang masuk dalam kuadran I, yaitu atribut koleksi buku sesuai dengan kebutuhan mahasiswa, atribut informasi penempatan buku sangat jelas dan mudah di temukan, atribut petugas perpustakaan memberikan kenyamanan terhadap mahasiswa, atribut pelayanan peminjaman buku dilayani dengan baik.

Usulan yang perlu untuk dilakukan perbaikan , terdapat 4 usulan, yaitu pihak perpustakaan Universitas Muhammadiyah Gresik menambah lagi koleksi buku-buku supaya lebih melengkapi yang dibutuhkan mahasiswanya, diharapkan petugas lebih memberikan informasi secara jelas kategori buku supaya mahasiswa yang pertama kali masuk ke perpustakaan Universitas Muhammadiyah Gresik tidak merasa kebingungan untuk mencari letak buku yang di butuhkan, sebaiknya penerapan 3s (senyum, sapa, salam) lebih di tekankan lagi terutama sektor pelayanan, dikarenakan dengan penerapan 3s (senyum, sapa, salam) kenyamanan mahasiswa saat mengunjungi perpustakaan akan lebih baik, petugas perpustakaan Universitas Muhammadiyah Gresik seharusnya mempunyai tata cara pelayanan agar saat penerapan pelayanan ke mahasiswa terus meningkat.

Saran untuk pengujian berikutnya sebaiknya menggunakan metode lain seperti Metode KanoQFD, Libqual, dan metode SWOT, hal ini untuk mengetahui output lain yang didapatkan

\section{DAFTAR PUSTAKA}

[1] K. H. Primayana, "Manajemen Sumber Daya Manusia Dalam Peningkatan Mutu Pendidikan Di Perguruan Tinggi," pp. 1-9, 2016.

[2] J.-A. Kim, "User perception and use of the academic library : A Correlation Analysis," The Journal of Academic Librarianship, vol. 8, no. 1, pp. 209-2015, 2017.

[3] Basuki and Sulistyo, Pengantar Ilmu Perpustakaan, Jakarta: Gramedia, 1993.

[4] S. Basuki, Metode Penelitian, Jakarta: Wedatama Widya Sastra, 2015.

[5] Komarudin, "Akreditasi Perpustakaan Perguruan Tinggi : Pengalaman Perpustakaan Stain Kediri," Pustakaloka, p. 8, 2016.

[6] Perpustakaan Nasional RI, 2018.

[7] P. Tiong, "Pengaruh kualitas pelayanan terhadap loyalitas pelanggan pt. primagum sejati di makassar," Journal of Management \& Business, 2018.

[8] C. Lukita, S. Pranata and K. Agustin, "Metode Servqual Dan Importance Performance 
Analysis Untuk Analisa Kualitas Layanan Jasa Pendidikan Tinggi Pada Mahasiswa Di Cirebon," Jurnal Digit, 2020.

[9] H. Suprianto, "Hubungan Kualitas Pelayanan Administrasi Dengan Kepuasan Mahasiswa Universitas Muhammadiyah Palembang," JURNAL MANAJEMEN MUTU PENDIDIKAN, 2020.

[10] R. Fitriawan, D. Putra and C. Nugroho, "Analisis Komunikasi Birokrasi Atas Kualitas Layanan Publik di Wilayah Administrasi Kabupaten Bandung," Jurnal Komunikasi, 2017.

[11] Y. Siregar, "Pengaruh Kualitas Pelayanan Dan Fasilitas Terhadap Kepuasan Konsumen Motor Honda Capella Batam," 2021.

[12] M. Mustofa, Handoyo and D. Ernawati, "ANALISIS TINGKAT KUALITAS PELAYANAN JASA," 2017.

[13] S. Sany, K. Kuncorosidi and M. Sopiawadi, "QUALITY ANALYSIS OF SERVICE WITH SERVQUAL (SERVICE QUALITY) METHOD IN TINI CAKE CATERING \& COOKIES MALAYSIA RESTAURANT," DIMENSIA, 2020.

[14] R. Ramdan, "PENGARUH TINGKAT LIKUIDITAS DAN KONSERVATISME AKUNTANSI TERHADAP TINGKAT PENGHINDARAN PAJAK (TAX AVOIDANCE)," 2020.

[15] D. W. Prasetyo, "Tingkat Kepuasan Siswa Dalam Menggunakan Jasa Pelayanan Perpustakaan Sekolah Di Man Yogyakarta III.," 2016.

[16] A. Juniyanto, "TINGKAT KEPUASAN MAHASISWA DALAM MENGGUNAKAN JASA PELAYANAN PERPUSTAKAAN FIK UNY.," 2013.

[17] N. E. Rozanda and D. Agusman, "Analisis Kualitas Pelayanan Perpustakaan Dalam Penerapan Sistem Informasi Perpustakaan," Jurnail Sains, Teknologi dan Industri, pp. 77 84, 2012.

[18] Nurmalasari, "Tingkat Kepuasan Mahasiswa Dalam Menggunakan Jasa Pelayanan
Perpustakaan Universitas Bina Sarana Informatika Pontianak. Jurnal Ilmiah Ekonomi dan Bisnis," Jurnal Ilmiah Ekonomi dan Bisnis, pp. 93-98, 2019.

[19] Perpustakaan Nasional RI, 2012.

[20] Perpustakaan Universitas Muhammadiyah Gresik, Gresik, 2020. 